\title{
PENGARUH LAMA FERRMENTASI DAN PEMBERIAN NATRIUM KARBONAT (Na2CO3) PADA MUTU BIJI KAKAO (Theobroma cacao L.)
}

\author{
Bukhari \\ Program Studi Agroteknologi \\ Fakultas Pertanian Universitas Jabal Ghafur
}

\begin{abstract}
ABSTRAK
Penelitian ini bertujuan untuk mengetahui pengaruh lama fermentasi dan pemberian Natrium Karbonat (Na2CO3) serta interaksinya terhadap mutu biji kakao (Theobroma cacao L). Penelitian ini dilaksanakan di Laboratorium Tehnik Pasca Panen Jurusan Tehnik Pertanian dan laboratorium Analisis pangan dan Pengolahan Pasca Panen Jurusan Teknologi Hasil Pertanian Fakultas Pertanian Universitas Syiah Kuala, Banda Aceh. Pelaksanaan penelitian berlangsung dari tanggal 25 Agustus s/d tanggal 3 September 2015, menggunakan Rancangan Acak Lengkap (RAL) faktorial. Faktor yang diteliti ada 2 yaitu faktor lama fermentasi (L) ada 4 taraf yaitu : L1 $=0$ (tanpa fermentasi), L2 $=2$ hari fermentasi, L3 = 4 hari fermentasi, $\mathrm{L} 4=6$ hari fermentasi. Faktor pemberian $\mathrm{Na} 2 \mathrm{CO} 3$ (A) ada 4 taraf yaitu : $\mathrm{A} 0=0 \%$, $\mathrm{A} 1=2 \%, \mathrm{~A} 2=4 \%, \mathrm{~A} 3=6 \%$. Dengan demikian terdapat 16 kombinasi perlakuan dengan 2 ulangan, sehingga diperoleh 32 satuan percobaan. Parameter yang diamati meliputi kadar air, lemak, pH, ALB dan Uji Organoleptik. Pengukuran $\mathrm{pH}$ menggunakan $\mathrm{pH}$ meter, asam lemak bebas (ALB) diukur dengan menggunakan metoda Sudarmadji et al., 1996. dan uji organoleptik.

Hasil pengamatan menunjukkan Lama fermentasi berpengaruh nyata, perlakuan alkalisasi serta interaksi keduanya tidak berpengaruh nyata terhadap kadar air. Perlakuan terbaik untuk kadar air adalah fermentasi 4 hari. Lama fermentasi, perlakuan alkalisasi, dan interaksi keduanya berpengaruh nyata terhadap kadar lemak biji kakao yang dihasilkan. Kadar lemak tertinggi terdapat pada perlakuan fermentasi 6 hari yaitu 50,36\%. Sedangkan kadar lemak terendah terdapat pada perlakuan 2 hari fermentasi dan alkalisasi yaitu 48,92\%. Perlakuan terbaik untuk lemak adalah fermentasi 6 hari dan alkalisasi. Lama fermentasi, perlakuan alkalisasi, dan interaksi keduanya berpengaruh nyata terhadap $\mathrm{pH}$ biji kakao. pH biji kakao setelah fermentasi berkisar antara 5,1-5,24, sedangkan pH setelah alkalisasi berkisar antara 6,53-6,88. Perlakuan terbaik untuk $\mathrm{pH}$ adalah fermentasi 4 hari dan alkalisasi. Lamanya fermentasi, alkalisasi, dan interaksi keduanya berpengaruh nyata terhadap Asam Lemak Bebas (ALB) yang ada pada biji kakao. ALB terendah ada pada fermentasi 4 hari dan setelah alkalisasi sedangkan yang tertinggi adalah pada biji kakao yang tidak mengalami perlakuan fermentasi. Perlakuan terbaik untuk asam lemak bebas adalah fermentasi 4 hari dan alkalisasi. Warna biji kakao yang dominan dipilih oleh para panelis pada uji organoleptik adalah warna coklat, aroma yang dominan dipilih adalah aroma khas coklat, tekstur yang dominan dipilih adalah agak halus, sedangkan untuk tingkat kerapuhan panelis dominan memilih agak rapuh.
\end{abstract}

Kata kunci : lama fermentasi, natrium karbonat, biji kakao

\section{Latar Belakang}

Kakao merupakan salah satu komuditi perkebunan primadona Provinsi Aceh. Hampir keseluruhan areal perkebunan kakao adalah perkebunan rakyat. Terdapat beberapa daerah yang menjadi areal penanaman kakao di Aceh, seperti Kabupaten Pidie, Kabupaten Pidie Jaya, dan Kabupaten Aceh tenggara. Perkembangan kakao cukup pesat karena memiliki nilai ekonomis yang tinggi yaitu buahnya dapat dijual dalam bentuk utuh maupun olahan (Herman dan Wardani, 2004).

Perkembangan produksi kakao tidak diikuti dengan perbaikan mutu biji kakao, hal ini juga terjadi di Aceh yang merupakan salah satu sentra produksi kakao di Indonesia untuk saat ini. Biji kakao dari perkebunan rakyat cenderung masih bermutu rendah. Rendahnya mutu biji kakao terutama disebabkan karena cara pengolahan yang kurang baik seperti halnya proses fermentasi yang kurang baik, pengeringan, sortasi dan pengepalan (Herman dan Wardani, 2004).

Fermentasi merupakan inti dari proses pengolahan biji kakao, proses ini tidak hanya bertujuan untuk membebaskan biji kakao dari pulp dan mematikan biji, namun terutama juga untuk memperbaiki dan membentuk citarasa coklat yang enak dan menyenangkan serta 
mengurangi rasa sepat dan pahit pada biji (Widyotomo, dkk, 2004).

Fermentasi sesungguhnya dapat dilakukan dengan mudah, metode fermentasi yang dapat dilakukan adalah fermentasi tumpukan, fermentasi dalam keranjang, dan fermenttasi dalam kotak atau peti kayu. Perbedaan dari metode tersebut hanya pada wadah atau tempat yang digunakan Widyotomo dan Sukrisno, 2008).

Fermentasi yang sempurna menentukan citarasa biji kakao dan produk olahannya. Mutu olahan kakao juga dipengaruhi oelh kesehatan buah dan tingkat kematangan buah disamping itu juga proses pengeringan yang baik. Jika fermentasi yang dilakukan kurang atau tidak sempurna, selain cita rasa khas kakao yang tidak terbentuk juga sering kali di ikuti cira rasa ikutan yang tidak dikehendaki seperti rasa asam, pahit, kelat, sangit, dan rasa tanah (Atman, 2006).

Bubuk kakao merupakan salah satu hasil olahan kakao yang paling banyak diproduksi baik untuk bahan makanan maupun minuman. Mutu bubuk kakao sangat dipengaruhi oleh warna dan rasa untuk itu pada tahapan proses pengolahan biji kakao setelah difermentasi dilakukan proses alkalisasi. Proses alkalisasi terhadap biji kakao dapat menyebabkan perubahan warna dan rasa kakao menjadi lebih baik. Namun berapa lama fermentasi yang baik dan berapa banyak pemberian Natrium diberikan untuk menghasilkan kakao yang berkualitas menghendaki suatu penelitian.

\section{Tujuan Penelitian}

Penelitian ini bertujuan untuk:

1. Mendeteksi pengaruh lama fermentasi.

2. pemberian Natrium Karbonat ( $\mathrm{Na} 2 \mathrm{CO} 3)$.

3. interaksinya terhadap mutu biji kakao.

\section{Hipotesis}

1. Diduga lama fermentasi berpengaruh terhadap mutu biji kakao

2. Diduga pemberian $\mathrm{Na} 2 \mathrm{CO} 3$ berpengaruh terhadap mutu biji kakao

3. Diduga terdapat interaksi antara lama fermentasi dan pemberian $\mathrm{Na} 2 \mathrm{CO} 3$ terhadap mutu biji kakao

\section{Manfaat penelitian}

Penelitian ini diharapkan dapat bermanfaat untuk pengembangan ilmu pengetahuan, khususnya pengolahan biji kakao.
Pada penelitian ini juga diharapkan dapat menambah pengetahuan petani khusunya di Aceh yang merupakan salah satu kawasan penegmbangan kakao di Indonesia agar dapat menghasilkan biji kakao yang lebih bermutu dan dapat bersaing baik secara nasional internasional, sehingga dapat meningkatkan taraf hidup petani.

\section{METODE PENELITIAN}

\section{Tempat dan Waktu}

Penelitian ini dilakukan di Laboratorium Tehnik Pasca Panen Jurusan Tehnik Pertanian dan laboratorium Analisis pangan dan Pengolahan Pasca Panen Jurusan Teknologi Hasil Pertanian Fakultas Pertanian Universitas Syiah Kuala, Banda Aceh., dilaksanakan pada tanggal 25 bulan Agustus 2015 s/d tanggal 3 bulan September 2015.

\section{Bahan dan Alat}

Bahan yang digunakan pada penelitian ini adalah buah kakao lindak (Umur Panen 5-6 bulan dari berbunga) yang berasal dari Teuping Raya Kabupaten Pidie dan Larutan Na2CO3 dengan konsentrasi $4 \%$.

Alat-alat yang digunakan dalam penelitiani ini adalah timbangan, wadah fermentasi (fermentor) berupa keranjang bambu, dan gelas ukur, alat tulis menulis.

\section{Model Rancangan}

Penelitian ini dilakukan dengan Rancangan Acak Lengkap (RAL) dalam bentuk faktorial. Faktor yang diteliti ada 2 faktor yaitu lama fermentasi dan faktor pemberian $\mathrm{Na} 2 \mathrm{CO} 3$ masing-masing 4 taraf yaitu sebagai berikut :

Faktor lama fermentasi adalah (L) sebanyak 4 taraf yaitu:

$\mathrm{L} 1=0$ (tanpa fermentasi)

$\mathrm{L} 2=2$ hari fermentasi

$\mathrm{L} 3=4$ hari fermentasi

$\mathrm{L} 4=6$ hari fermentasi

Faktor pemberian $\mathrm{Na} 2 \mathrm{CO} 3$ (A) sebanyak 4 taraf yaitu :

$\mathrm{A} 0=0 \%$

$\mathrm{A} 1=2 \%$

$\mathrm{A} 2=4 \%$

$\mathrm{A} 3=6 \%$

Dengan demikian terdapat 16 kombinasi perlakuan dengan 2 ulangan, sehingga diperoleh 32 satuan percobaan. Model metematika sebagai berikut : 
$Y_{i j k}=\mu+\mathrm{Li}+\mathrm{Aj}+(\mathrm{LAij})+\Sigma_{\mathrm{ijk}}$

Dimana :

Ýijk : Hasil Pengamatan

$\mu \quad$ : Efek Nilai Tengah

Li : Efek dari Lama Fermentasi dari Taraf Ke-i

Aj : Efek dari Kosentrasi Na2CO3 Lama Fermentasi pada Taraf ke-j

(LA)ij : Efek Interaksi dari Lama Fermentasi pada Taraf ke-i dengan konsentrasi $\mathrm{Na} 2 \mathrm{CO} 3$ pada Taraf ke-j

Lijk : Efek Error dari Lama Fermentasi pada Taraf ke-i dengan konsentrasi Na2CO3 pada Taraf ke-j

Bila terdapat perbedaan nyata maka dilanjutkan dengan uji lanjut Duncan

Tabel 4. Susunan Kombinasi Perlakuan Lama Fermentasi dan Pemberian Na2CO3 Seperti Tertera Dibawah Ini :

\begin{tabular}{ccc}
\hline $\begin{array}{c}\text { Kombinasi } \\
\text { Perlakuan }\end{array}$ & $\begin{array}{c}\text { Lama } \\
\text { Fermentasi } \\
\text { (hari) }\end{array}$ & $\begin{array}{c}\text { Pemberian } \\
\mathrm{Na}_{2} \mathrm{CO}_{3}(\%)\end{array}$ \\
\hline $\mathrm{L}_{0} \mathrm{~A}_{0}$ & 0 & 0 \\
$\mathrm{~L}_{0} \mathrm{~A}_{1}$ & 0 & 2 \\
$\mathrm{~L}_{0} \mathrm{~A}_{2}$ & 0 & 4 \\
$\mathrm{~L}_{0} \mathrm{~A}_{3}$ & 0 & 6 \\
$\mathrm{~L}_{1} \mathrm{~A}_{0}$ & 2 & 0 \\
$\mathrm{~L}_{1} \mathrm{~A}_{1}$ & 2 & 2 \\
$\mathrm{~L}_{1} \mathrm{~A}_{2}$ & 2 & 4 \\
$\mathrm{~L}_{1} \mathrm{~A}_{3}$ & 2 & 6 \\
$\mathrm{~L}_{2} \mathrm{~A}_{0}$ & 4 & 0 \\
$\mathrm{~L}_{2} \mathrm{~A}_{1}$ & 4 & 2 \\
$\mathrm{~L}_{2} \mathrm{~A}_{2}$ & 4 & 4 \\
$\mathrm{~L}_{2} \mathrm{~A}_{3}$ & 4 & 6 \\
$\mathrm{~L}_{3} \mathrm{~A}_{0}$ & 6 & 0 \\
$\mathrm{~L}_{3} \mathrm{~A}_{1}$ & 6 & 2 \\
$\mathrm{~L}_{3} \mathrm{~A}_{2}$ & 6 & 4 \\
$\mathrm{~L}_{3} \mathrm{~A}_{3}$ & 6 & 6 \\
\hline
\end{tabular}

\section{Prosedur Penelitian}

1. Buah kakao yang sudah matang disortasi, kemudian diperam selama 5 hari. pemeraman ini bertujuan agar kematangan buah kakao seragam.

2. Setelah diperam, buah kakao dipecah untuk memisahkan kulit dengan isi. Dalam pemecahan buah dilakukan dengan menggunakan pemukul kayu atau memukul yang satu dengan yang lainnya. Bisa juga digunakan pisau tetapi tidak memotong terlalu dalam agar tidak terkena biji

3. Wadah kotak atau lokasi penumpukkan biji kakao dibersihkan untuk menghindari kontaminasi aleh bakteri pembusuk.

4. Kemudian wadah dan tempat fermentasi dilapisi dengan daun pisang.

5. Biji kakao yang dihasilkan dimasukkan dalam keranjang bambu atau ditumpuk ditempat yang teduh.

6. Setelah penempatan biji pada wadah, biji ditutup kembali dengan pembungkus untuk dilakukan proses fermentasi.

7. Fermentasi berangsung sesuai dengan cara menumpuk $5 \mathrm{~kg}$ biji kakao pada setiap keranjang.

8. Fermentasi berlangsung sesuai dengan perlakuan 0, 2, 4 dan 6 hari. Setelah 48 jam biji kakao dibalik

9. Biji kakao dibersihkan, dicuci dan dikeringkan dibawah sinar matahari.

10. Biji kakao (yang mendapat perlakuan fermentasi) kering kemudian dicelupkan selama 30 menit ke dalam larutan natrium karbonat (Na2CO3) dengan konsentrasi $4 \%$.

11. Biji diangin-anginkan.

\section{Pelaksanaan Penelitian}

Biji kakao yang digunakan adalah biji kakao yang dipisahkan dari kulitnya. Biji kakao kemudian dibawa ke Laboratorium Pasca Panen Tehnik Pertanian Fakultas Pertanian Universitas Syiah Kuala, Banda Aceh.

Biji kakao dipisahkan antara biji kakao yang tidak difermentasi, fermentasi tidak sempurna, fermentasi sempurna, dan untuk fermentasi dengan waktu yang berlebihan. Fermentasi dilakukan dengan menggunakan keranjang bambu, setiap keranjang diisi $5 \mathrm{~kg}$ biji kakao. Setelah difermentasi kakao dicuci, dikeringkan, dan dibersihkan dari sisa-sisa kulit bijinya. Lalu ditimbang masing-masing 100 gram dan dimasukkan dalam larutan $\mathrm{Na} 2 \mathrm{CO} 3$ yang dilarutkan dengan air hangat (800C) dengan konsentrasi $2 \%, 4 \%$ dan $6 \%$. perbandingannya biji kakao dengan larutan adalah 1:5, dengan masing-masing perlakuan direndam selama 30 menit. Setelah itu ditiriskan dan diangin-anginkan.

\section{Pengamatan Analisis}

Parameter yang diamati daam penelitian ini meliputi : kadar air, $\mathrm{pH}$, lemak, asam lemak bebas, uji tingkat kerapuhan biji. 


\section{Kadar Air}

Pengukuran Kadar air dilakakn seperti yang telah dilaksanakan oleh Purwanti (2004) dengan langkah-langkah seperti beriku: Sampel dikeringkan dalam oven pada suhu 1050C sehingga diperoleh berat yang tetap. Cara Kerja :

a. Cawan kosong dan ditutupnya dikeringkan dalam oven selama 15 menit dan didinginkan dalam desikator, kemudian ditimbang (untuk cawan aluminium didinginkan selama 10 menit dan cawan porselin didinginkan selama 20 menit).

b. Sampel yang sudah dihomogenkan dengan cawan ditimbang dengan cepat kurang lebih 5 gram.

c. Tutup cawan diangkat dan ditempatkan cawan beserta isi dan tutupnya dalam oven selama 5 jam, hindari kontak antara cawan dengan dinding oven, untuk produk yang tidak mengalami dekomposisi dengan pengeringan yang lama, dapat dikeringkan selama semalam (16 jam).

d. Cawan dipindahkan ke desikator, ditutup dengan penutup cawan lalu didinginkan, selama dingin ditimbang kembali.

e. Bahan dikeringkan kembali kedaam oven sampai diperoleh berat tetap

$\mathrm{M}(\mathrm{bb})=\mathrm{W} 1-\mathrm{W} 2$

W1

Keterangan :

$\mathrm{M}(\mathrm{bb}) \quad=$ Kadar air basis basah (\%)

W1 = Berat awal bahan (gr)

$\mathrm{W} 2=$ Berat akhir bahan (gr)

\section{Lemak}

Lemak diekstraksi dengan metode Soxhlet seperti yang dilakukan oleh Purwanti ( 2004)

a. Diambil abu lemak yang ukurannya sesuai dengan alat ekstraksi Soxhlet yang digunakan, dikeringkan dalam oven, didinginkan dalam desikator, dan ditimbang.

b. Ditimbang 5 gram sampel dalam bentuk tepung langsung dalam saringan timbel yang sesuai ukuranya, kemudian ditutup dengan kapas-wool yang bebas lemak. sebagai alternatif sampel dapat dibungkus dengan kertas kering. c. diletakkan timbel atau kertas saring yang berisi sampel tersebut dalam alat ekstraksi Soxhlet, kemudian dipasang alat kondensor di atasnya dan abu lemak dibawahnya.

d. dituangkan pelarut dietil atau petroleum eter kedalam abu lemak secukupnya, sesuai dengan ukuran Soxhlet yang digunakan.

e. Dilakukan refluks selama minimum 5 jam sampai pelarut yang diturun kembali ke labur lemak berwarna jernih.

f. Distilasi pelarut yang ada didalam abu lemak ditampung pelarutnya. Selanjutnya abu lemak yang berisi lemak hasil ekstraksi dipanaskan dalam oven pada suhu $1050 \mathrm{C}$.

g. Setelah dikeringkan sampai berat tetap dan didinginkan dalam desikator, ditimbang labu beserta lemaknya tersebut. Berat lemak dapat dihitung :

$$
\begin{gathered}
\% \text { Lemak }=\text { Berat Lemak }(\text { gram }) \times 100 \% \\
\text { Berat Sampel }
\end{gathered}
$$

\section{Pengukuran $\mathbf{p H}$ Menggunakan $\mathrm{pH}$ Meter}

Kalibrasi pH meter. Siapkan sampel larutan yang akan di check pH-nya. Jika larutan panas, biarkan larutan mendingin sampai dengan suhunya sama dengan suhu ketika kalibrasi. Contohnya jika kalibrasi dilakukan pada suhu 200C maka pengukuran pun dilakukan pada suhu 200C. Buka penutup plastik elektroda, bilas dengan air dan keringkan dengan menggunakan kertas tisu. Nyalakan $\mathrm{pH}$ meter dengan menekan tombol ON/OFF. Masukan elektroda kedalam sampel, kemudian putar agar larutan homogeny. Tekan tombol MEAS untuk memulai pengukuran, pada layar akan muncul tulisan HOLD yang kelap-kelip. Biarkan sampai tulisan HOLD pada layar berhenti kelap-kelip. Nilai $\mathrm{pH}$ yang ditunjukan pada layar adalah nilai $\mathrm{pH}$ larutan yang di check. Matikan $\mathrm{pH}$ meter dengan menekan kembali tombol ON/OFF.

\section{Pengukuran Asam Lemak Bebas (ALB).}

Kadar asam lemak bebas (ALB) diukur dengan menggunakan metoda Sudarmadji et al., 1996. Dengan langkah sebagai berikut ; Sampel yang telah ditimbang sebanyak 10 gram dimasukkan dalam erlenmeyer $200 \mathrm{ml}$ dan tambahkan $50 \mathrm{ml}$ alkohol netral $95 \%$. kemudian dipanaskan selama 10 menit sambil diaduk. setelah didinginkan, larutan dititrasi dengan $\mathrm{KOH} \quad 0,1 \quad \mathrm{~N}$ menggunakan indikator 
phenolphthalein $1 \%(\mathrm{PP})$ sampai terlihat warna merah jambu. Kadar asam lemak bebas (\% FFA) dapat dihitung dengan menggunakan rumus sebagai berikut

Kadar Asam Lemak Bebas $=m l \mathrm{KOH}$ x N $\mathrm{KOH} \times 200 \times 100 \%$

sampel (gram) x 1000

Bobot

\section{Uji Organoleptik}

Uji Organoleptik didasarkan pada penguji rasa oleh panelis yang pekerjaannya mengamati, menguji, dan menilai secara organoleptik. Pengujian organoleptik dilakukan secara deskriptif dengan jumlah panelis 25 orang. Pengujian tersebut dilakukan pada biji kakao yang mendapat perlakuan fermentasi maupun alkalisasi dengan kriteria uji berdasarkan mutu warna, aroma, tekstur, dan kerapuhan.

\section{HASIL DAN PEMBAHASAN Kadar Air}

Hasil penelitian diperoleh kadar air awal biji kakao sebesar 54,70\%, kadar air biji kakao yang diharapkan pada penelitian ini adalah $7,50 \%$ setelah biji dikeringkan dengan batasan maksimal kadar air 8\%. Acuan ini diambil berdasarkan Standar Nasional Indonesia untuk biji kakao. Pada penelitian ini kadar air biji kakao setelah dikeringkan berkisar antara 7,40\% - 7,85\% untuk setiap perlakuannya, seperti terlihat pada Gambar 1

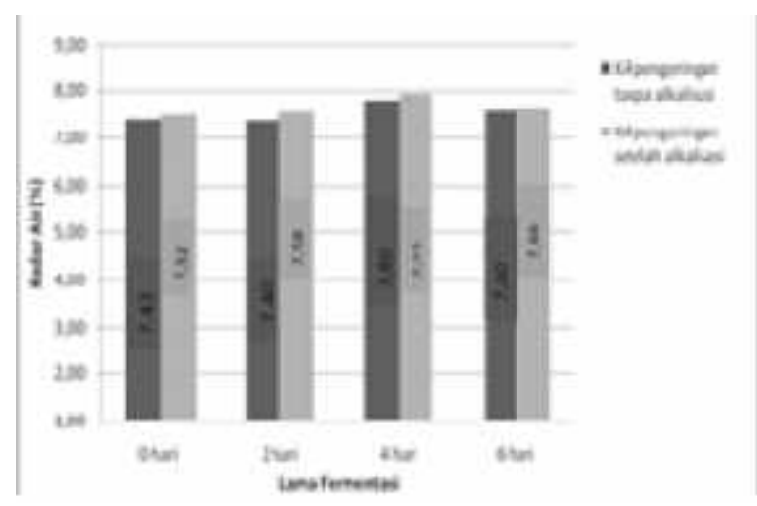

Gambar 1. Hubungan Kadar Air Biji Kakao Terhadap Lama Fermentasi dan Alkalisasi

Hasil analisis keragaman menunjukkan bahwa perlakuan lama fermentasi berpengaruh nyata, konsentrasi alkali dan interaksi keduanya tidak berpengaruh nyata terhadap kadar air biji kakao. Uji lanjut Duncan 5\% menunjukkan bahwa pengaruh lama fermentasi 4 hari berbeda nyata dengan lama fermentasi 0,2 dan 6 hari, seperti Gambar 2.

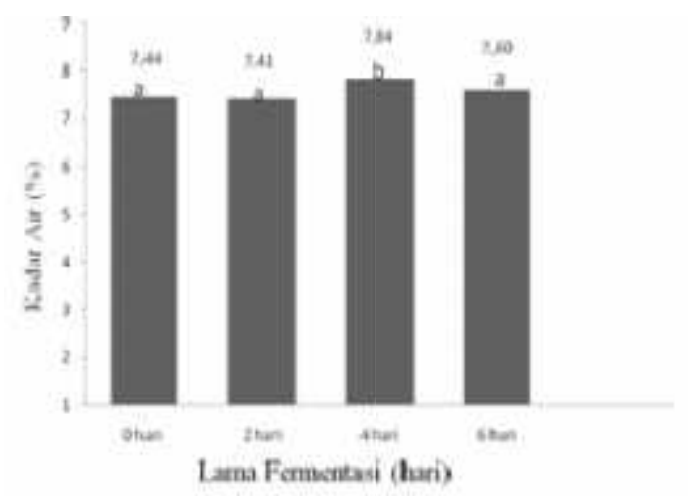

Gambar 2. Uji Lanjut Duncan Pengaruh Lama Fermentasi Terhadap Kadar Air Biji Kakao

Pada perlakuan dengan lama fermentasi 4 hari diperoleh kadar air tertinggi pada biji kakao yaitu $7,84 \%$. Hal ini diduga terjadi karena biji kakao masih dilapisi pulp pada hari keempat fermentasi, pulp yang melapisi biji kakao merupakan bagian dari biji kakao yang memiliki kandungan kadar air yang cukup banyak. Proses penguraian pulp berlangsung hingga hari kelima fermentasi, dimana pada hari kelima fermentasi pulp yang melapisi biji kakao sudah sangat sedikit bahkan hampir tidak ada sehingga kadar air biji kakao menjadi rendah.

Jika merujuk pada kadar air yang ditetapkan oleh Standar Nasional indonesia (SNI) maka biji kakao mutu I harus memiliki kadar air maksimal sebesar 7,5\%. Selama proses fermentasi 2, 4, dan 6 hari kadar air yang terbaik didapat pada proses fermentasi selama 4 hari dan alkalisasi yaitu sebesar 7,42\%.

Penurunan kadar air dengan semakin lama waktu fermentasi antara lain disebabkan oleh terurainya jaringan pulp pada saat proses fermentasi. Hancurnya pulp mempermudah keluarnya air selama proses pengeringan, selain itu selama proses fermentasi juga terjadi kematian biji yang mengakibatkan sifat semi permeabilitas dinding sel menjadi rusak sehingga memudahkan keluarnya air selama proses pengeringan (Dini, 2010)

Menurut Suryani (2007), pengeringan dilakukan sampai kadar air menjadi $7-8 \%$ (setimbang dengan udara berkelembaban 75\%). Kadar air kurang dari 6\%, biji akan rapuh sehingga penangganan serta pengolahan lanjutnya menjadi lebih sulit. Kadar air lebih dari 9\% memungkinkan pelapukan biji oleh jamur. 


\section{Lemak}

Kadar lemak biji kakao yang didapat pada penelitian ini untuk lama fermentasi 0-6 hari berkisar antara 49,92\% - 50,36\% sedangkan untuk biji kakao yang mengalami perlakuan fermentasi dan alkalisasi berkisar antara 48,92\% - 50,16\%, kadar lemak biji kakao pada penelitian ini dapat dilihat pada Gambar 6 .

Dari hasil penelitian dapat kita lihat kadar lemak terendah dimiliki oleh biji kakao dengan perlakuan fermentasi 2 hari dan alkalisasi, sedangkan kadar lemak tertinggi dimiliki oleh biji kakao dengan perlakuan fermentasi selama 6 hari dan tanpa alkalisasi.

Gambar 5 menunjukkan bahwa semakin lama proses fermentasi maka akan semakin tinggi kandungan lemak pada biji kakao tersebut, Rahman (1989) menyatakan bahwa proses fermentasi yang berlangsung anaerobik (tanpa oksigen) mengakibatkan mikroorganisme yang tumbuh pada proses fermentasi meningkatkan kandungan lemak dengan mengubah senyawa-senyawa seperti polifenol, protein dan gula. Mikroorganisme yang berperan dalam proses penguraian senyawa-senyawa tersebut adalah Streptococcus laktis dan Sacharomytes cerevisiae.

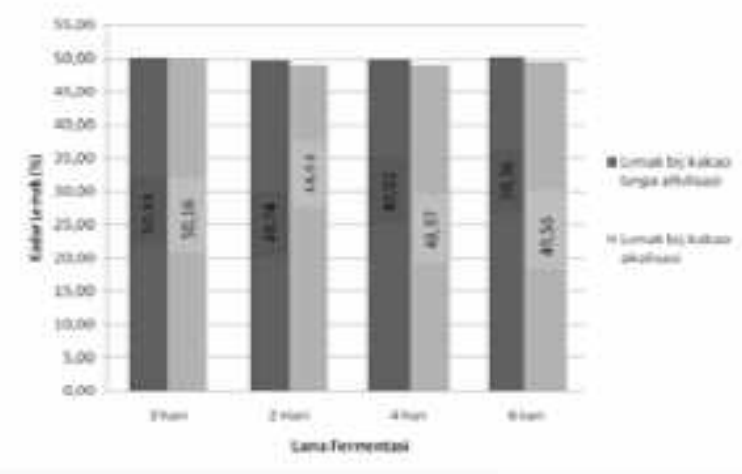

Gambar 5. Hubungan Lemak Biji kakao Terhadap Lama Fermentasi dan Alkalisasi

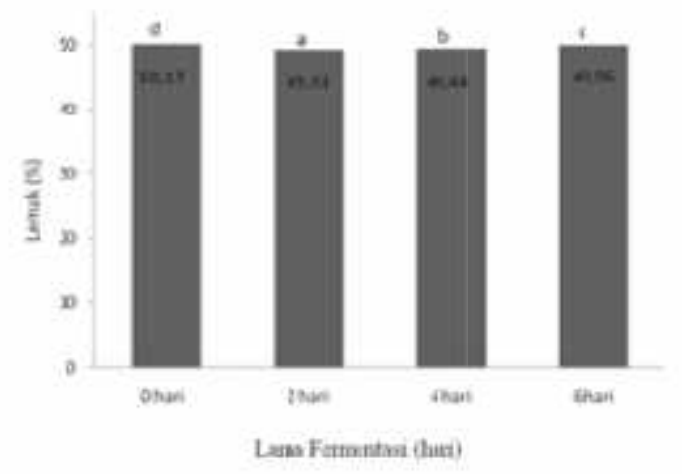

Gambar 6. Uji Lanjut Duncan 5\% Pengaruh Lama Fermentasi Terhadap Lemak Biji Kakao
Hasil analisis keragaman didapat data bahwa lama fermentasi, penggunaan alkali, serta interaksi keduanya juga menunjukkan adanya pengaruh yang nyata pada konsentrasi lemak biji kakao. Uji Duncan 5\% didapat bahwa lemak biji kakao yang difermentasi akan berbeda setiap harinya.

Proses alkalisasi akan menurunkan kadar lemak biji kakao, penurunan ini bisa disebabkan karena larutan alkali bersifat lipofilik yaitu mampu menyerap lemak sehingga kadar lemak pada biji kakao berkurang.

Kadar lemak dalam biji kakao adalah $53,05 \%$ hal ini tidak dicapai oleh perlakuan manapun tetapi kadar lemak yang paling mendekati adalah 50,36\% pada fermentasi 6 hari dan tanpa alkalisasi.

\section{pH}

pH biji kakao yang diperoleh pada penelitian ini berkisar antara 5,10-6,88 seperti tertera pada Gambar 5. pH yang paling menjauhi netral sebesar 5,10 adalah $\mathrm{pH}$ pada biji kakao dengan lama fermentasi 6 hari sedangkan $\mathrm{pH}$ yang sangat mendekati netral yaitu 6,88 didapat pada biji kakao yang tidak mengalami fermentasi tetapi mendapatkan perlakuan alkalisasi. pH biji kakao akan semakin menjauhi netral dengan semakin lamanya fermentasi, untuk menetralkan biji kakao akibat proses fermentasi maka dilakukan proses alkalisasi pada biji kakao. Gambar 4 menunjukkan bahwa $\mathrm{pH}$ biji kakao yang mendapat perlakuan alkalisasi cenderung mendekati netral hal ini terjadi karena larutan alkali yang bersifat basa mengakibatkan $\mathrm{pH}$ menjadi lebih netral.

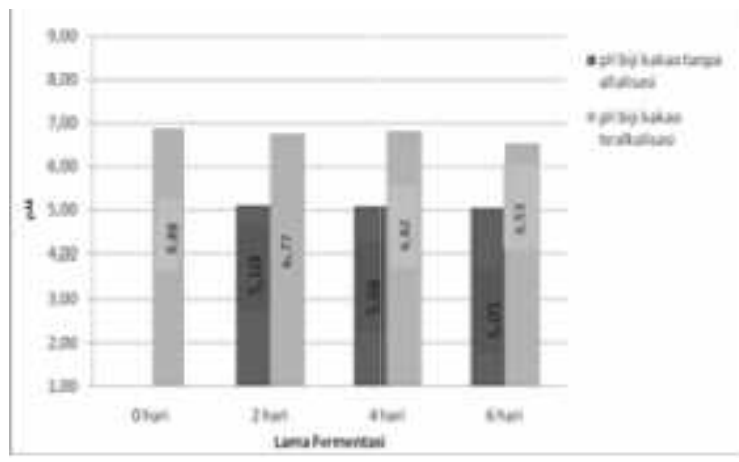

Gambar 3. Hubungan pH Biji Kakao Terhadap Biji Fermentasi dan Alkalisasi

Hasil analisis keragaman untuk pH biji kakao setelah proses fermentasi dan alkalisasi diketahui bahwa perlakuan lama fermentasi, konsentrasi alkali, dan interaksi keduannya juga berpengaruh nyata terhadap $\mathrm{pH}$ biji kakao. 
Uji lanjut Duncan 5\% diketahui bahwa pengaruh pH nyata terlihat pada biji kakao yang tidak difermentasi dengan biji kakao yang difermentasi selama 2, 4, dan 6 hari. $\mathrm{pH}$ fermentasi 6 hari berbeda nyata dengan fermentasi 2 dan 4 hari dan berbeda nyata dengan tanpa fermentasi seperti pada Gambar 4.

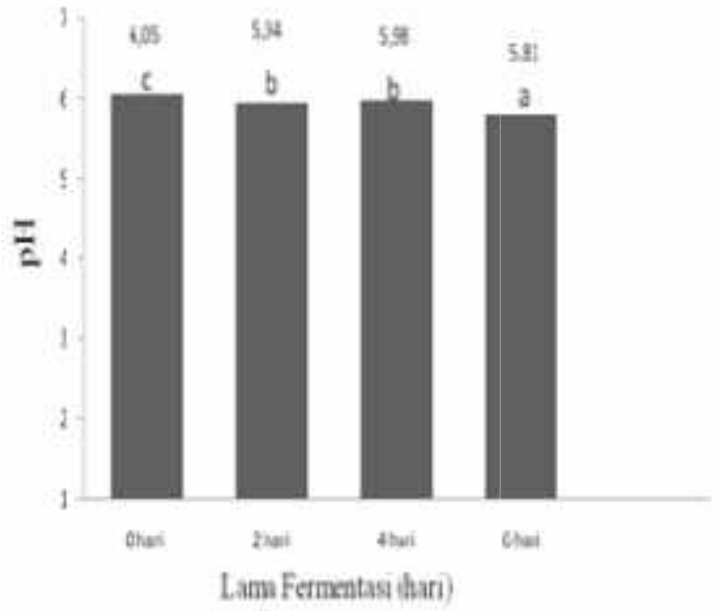

Gambar 4. Uji Lanjut Duncan 5\% Pengaruh Lama Fermentasi Terhadap pH Biji Kakao

Setelah fermentasi pH biji kakao semakin menjauhi $\mathrm{pH}$ netral dari sebelumnya ini menunjukkan selama proses fermentasi kandungan asam biji kakao meningkat. Setelah mengalami proses alkalisasi pengaruh terlihat sangat nyata dimana $\mathrm{pH}$ biji kakao meningkat menuju $\mathrm{pH}$ netral yaitu 7 , hal ini terjadi dikarenakan $\mathrm{pH}$ biji kakao yang menjauhi $\mathrm{pH}$ netral akibat proses fermentasi direndam pada larutan alkali yang basa sehingga menetralkan pH biji kakao.

Besarnya $\mathrm{pH}$ biji kakao dari $\mathrm{pH}$ netral setelah lama fermentasi 2 hari kemungkinan pertumbuhan mikroba yang menyebabkan terjadinya pembentukan asam meningkat sehingga asam yang dihasilkan semakin banyak. $\mathrm{pH}$ yang paling jauh dari $\mathrm{pH}$ netral adalah $\mathrm{pH}$ yang dimiliki oleh biji kakao yang difermentasi selama 6 hari dan tidak mendapat perlakuan alkalisasi hal ini semakin menunjukkan semakin lama fermentasi akan meningkatkan pertumbuhan mikroba yang meningkatkan kadar asam kakao. Kadar air yang semakin sedikit juga mengakibatkan $\mathrm{pH}$ biji kakao menjauhi netral karena keasaman biji kakao akan berkurang akibat adanya air yang dimiliki biji kakao. Pengaruh alkalisasi juga sangat terlihat pada $\mathrm{pH}$ biji kakao, dimana $\mathrm{pH}$ biji kakao yang mendapat perlakuan alkalisasi memiliki $\mathrm{pH}$ yang mendekati $\mathrm{pH}$ netral. Merujuk pada $\mathrm{pH}$ netral 7 kita dapat melihat bahwa perlakuan 4 hari fermentasi dengan alkalisasi adalah yang terbaik untuk penelitian ini karena mampu menghasilkan $\mathrm{pH}$ yang hampir mendekati netral yaitu 6,82 .

Widyotomo dan Muluto (2004) menyatakan bahwa, pada dasarnya semua biji kakao mengandung asam-asam volatil dan non volatil. Diantara jenis asam yang paling dominan adalah asam asetat, asam sitrat dan asam laktat. Jumlah asam-asam ini berkisar 1$2 \%$ adanya asam-asam tersebut dalam jumlah yang paling banyak mempengaruhi reaksi-reaksi pembentukan calon cita rasa coklat.

\section{Asam Lemak Bebas}

Hasil penelitian menunjukkan untuk perlakuan fermentasi diperoleh kandungan asam lemak bebas (ALB) untuk mutu biji kakao berkisar antara $1,59 \%-1,96 \%$ sedangkan untuk perlakuan alkalisasi asam lemak bebas (ALB) berkisar antara 1,42\%-1,83\%.

Biji kakao yang mendapat perlakuan fermentasi memiliki kadar asam lemak bebas yang akan meningkat setiap harinya hal ini terlihat pada Gambar 8 bahwa biji kakao dengan lama fermentasi 6 hari memiliki kadar asam lemak bebas sebesar $1,78 \%$, pengaruh proses alkalisasi juga dapat kita lihat pada Gambar 8 dimana setiap perlakuan alkalisasi menurunkan kadar asam lemak bebas setelah proses fermentasi.

Proses alkalisasi dapat menurunkan kadar lemak, jika kadar lemak turun maka kadar asam lemak bebas biji kakao juga akan turun karena asam lemak bebas merupakan komponen penyusun lemak.

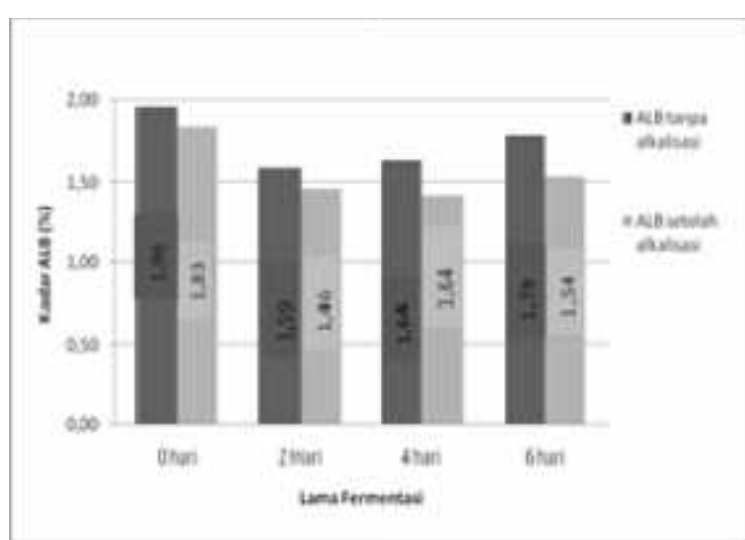

Gambar 7. Hubungan Asam Lemak Bebas (ALB) Biji Kakao Terhadap Lama Fermentasi dan Alkalisasi

Hasil analisis keragaman didapat data bahwa lama fermentasi berpengaruh nyata, 
konsentrasi alkali berpengaruh nyata, dan interaksi keduanya juga berpengaruh nyata terhadap konsentrasi asam lemak bebas pada biji kakao.

Uji lanjut menggunakan Duncan 5\% didapat bahwa pada perlakuan fermentasi dengan lama 0,2 , 4, dan 6 hari, konsentrasi asam lemak bebas pada biji kakao yang difermentasi selama 2 hari berbeda nyata dengan biji kakao dengan lama fermentasi 4 dan 6 hari dan berbeda nyata dengan biji kakao yang tidak difermentasi seperti pada Gambar 8.

Semakin lama proses fermentasi maka akan meningkatkan kadar asam lemak bebas pada biji kakao, meningkatnya asam lemak bebas mengakibatkan turunya mutu biji kakao tersebut sehingga diperlukan perlakuan tambahan, alkalisasi menjadi salah satu perlakuan yang dapat menurunkan kadar asam lemak bebas biji kakao yang telah difermentasi.

Berdasarkan mutu lemak kakao pada SNI (2000) maka kadar maksimal asam lemak bebas biji kakao maksimal adalah $1,75 \%$, untuk semua perlakuan pada penelitian ini hanya fermentasi 6 hari dengan tanpa alkalisasi yang melebihi batas maksimal tersebut yaitu $1,78 \%$. Kadar asam lemak bebas yang terbaik didapat pada perlakuan fermentasi 4 hari dan alkalisasi yaitu $1,42 \%$.

Tingginya kandungan asam lemak bebas kakao menunjukkan bahwa asam lemak bebas yang besar di dalam kakao yang berasal dari hidrolis lemak. Semakin tinggi bilangan asam suatu produk maka akan makin rendah kualitas produk tersebut, karena keberadaan asam lemak bebas di dalam lemak kakao merupakan salah satu indikator kerusakan mutu. Semakin lama waktu fermentasi maka kandungan asam lemak bebas juga semakin menurun, hal ini di diduga karena tumbuhnya mikroba yang dapat menghidrolisasi lemak pada biji sehingga akan menghasilkan dan rasa yang tidak enak (Puziah, 2005)

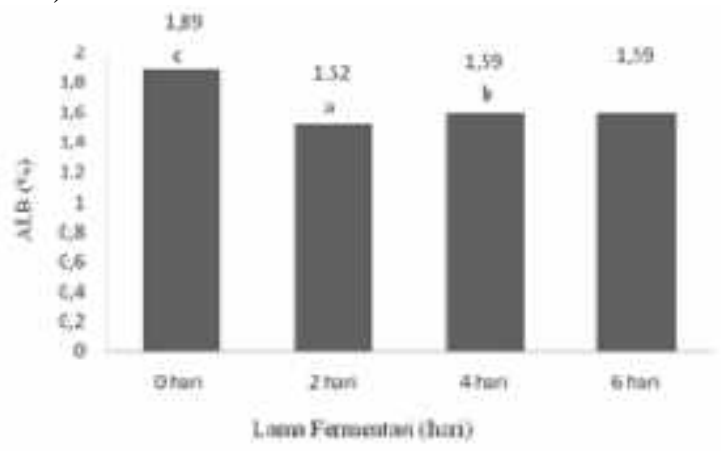

Gambar 8. Uji Lanjut Duncan 5\% Pengaruh Lama Fermentasi Terhadap Asam Lemak Bebas Biji Kakao

\section{Uji Organoleptik}

Uji Organoleptik biji kakao meliputi aroma, warna, tekstur, dan tingkat kerapuhan biji kakao. Panelis yang digunakan adalah mahasiswa dan mahasiswi yang berjumlah 25 orang. Pengujian dilakukan baik pada biji kakao yang telah mendapat perlakuan fermentasi selama $0,2,4$, dan 6 hari, juga biji kakao yang telah difermentasi dan alkalisasi. Keseluruhan dari hasil uji organoleptik terhadap biji kakao tersebut dapat dilihat pada grafik jaring labalaba berikut ini:

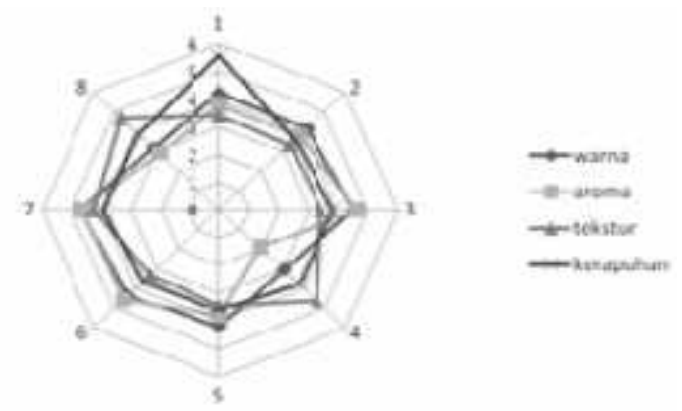

Gambar 9. Grafik Jaring Laba-Laba Biji Kakao

Keterangan :

1. Fermentasi 0 hari 2. Fermentasi 0 hari tanpa alkalisasi dengan alkalisasi

3. Fermentasi 2 hari 4. Fermentasi 2 hari tanpa alkalisasi dengan alkalisasi

5. Fermentasi 4 hari 6. Fermentasi 4 hari tanpa alkalisasi dengan alkalisasi

7. Fermentasi 6 hari 8. Fermentasi 6 hari tanpa alkalisasi dengan alkalisasi

Berdasarkan Gambar di atas dapat kita lihat bahwa untuk biji kakao yang tidak mengalami perlakuan fermentasi mendapat penilaian yang berbeda dari masing-masing panelis. Untuk warna yang paling banyak dipilih oleh panelis adalah warna agak coklat dengan rata-rata nalai 4,16, untuk aroma yang yang paling banyak dipilih adalah sangat tidak menyengat dengan rata-rata nilai 3,76, tekstur yang paling banyak dipilih adalah kasar dengan rata-rata nilai 3,32, sedangkan untuk tingkat kerapuhannya yang paling banyak dipilih adalah agak rapuh dengan rata-rata nilai 3,59.

Biji kakao yang tidak difermentasi namun mendapat perlakuan alkalisasi berdasarkan 
panelis rata-rata memilih memiliki warna agak coklat dengan rata-rata nilai yang dipilih panelis 4,21 , untuk biji kakao ini aroma yang paling banyak dipilih panelis adalah sangat tidak menyengat dengan rata-rata nilai yang dipilih panelis 3,81, untuk tekstur menurut panelis adalah kasar dengan rata-rata nilai 3,44, sedangkan untuk kerapuhan panelis memilih agak rapuh dengan rata-rata nilai 3,59.

Perlakuan lama fermentasi 2 hari tanpa alkalisasi para panelis memberikan penilaian untuk warna dengan warna agak coklat rata-rata nilainya adalah 4,33, untuk aroma pilihan panelis adalah tidak menyengat, aroma khas coklat/normal dengan rata-rata nilai 3,41 , kerapuhan yang dipilih adalah agak keras dengan rata-rata nilai 3,64.

Perlakuan lama fermentasi 2 hari dan alkalisasi, warna yang dipilih para panelis untuk perlakuan ini adalah warna agak coklat dengan rata-rata nilai 4,38, untuk aroma biji kakao dengan perlakuan ini panelis memilih aroma tidak menyengat, aroma khas coklat/normal dengan rata-rata nilai 4,57 , untuk tekstur para panelis memilih kasar dengan rata-rata nilai 3,35, dan untuk kerapuhan panelis memilih agak keras dengan rata-rata nilai 3,65 .

Biji kakao dengan perlakuan fermentasi selama 4 hari, penilaian terhadap warna yang dipilih panelis adalah warna coklat dengan ratarata penilaian 4,54, untuk aroma panelis memilih tidak menyengat, aroma khas coklat/normal denga rata-rata penilaian 4,63, tekstur untuk biji kakao dengan perlakuan ini dinilai panelis dengan agak halus rata-rata nilai 4,11 dan untuk kerapuhan para panelis memilih agak keras dengan rata-rata nilai 3,84 .

Perlakuan lama fermentasi 4 hari dan alkalisasi pilihan panelis adalah warna coklat dengan rata-rata nilai 4,68 , untuk aroma panelis memilih tidak menyengat, aroma khas coklat/normal dengan rata-rata nilai 4,24, untuk kerapuhan biji kakao panelis memilih agak keras dengan rata-rata nilai 3,91.

Biji kakao dengan lama fermentasi 6 hari, untuk warna yang paling banyak dipilih oleh panelis adalah warna coklat kehitaman dengan rata-rata penilaian 3, 04, untuk aroma para panelis banyak memilih menyengat tercium lemah rata-rata nilai yang diberikan adalah 1,92, tekstur yang paling banyak dipilih untuk perlakuan ini adalah halus dengan rata-rata nilai 4,64, sedangkan untuk kerapuhan panelis paling banyak memilih agak rapuh dengan rata-rata nilai 3,76 .
Perlakuan lama fermentasi 6 hari dan alkalisasi, kebanyakan panelis memilih warna coklat kehitaman dengan rata-rata nilai 3,19 , aroma yang banyak dipilih oleh panelis adalah menyengat tercium lemah dengan rata-rata nilai 2,90 ,untuk tekstur yang banyak dipilih oleh panelis adalah halus dengan rata-rata nilai 4,72, sedangkan untuk kerapuhan penelis memilih agak rapuh dengan rata-rata nilai 3,68.

Uji organoleptik menunjukkan bahwa para panelis dominan memilih warna coklat untuk keseluruhan perlakuan yang diberikan pada biji kakao, hal ini dikarenakan warna biji kakao kering biasanya memiliki warna coklat apabila dikeringkan dengan baik dibawah sinar matahari. Untuk aroma biji kakao terdapat perbedaan antara biji kakao yang tidak difermentasi dengan yang telah difermentasi. Biji kakao yang difermentasi memiliki aroma khas coklat setelah mendapat perlakuan fermentasi baik selama 2, 4 dan 6 hari sedangkan perlakuan alkalisasi tidak berpengaruh pada aroma biji kakao. Tekstur juga dipengaruhi oleh lamanya fermentasi hal ini terlihat pada uji organoleptik untuk biji kakao yang difermentasi selama 2 hari berbeda dengan biji kakao yang difermentasi selama 4 hari dan 6 hari. Biji kakao yang difermentasi selama 6 hari memiliki tekstur agak halus sedangkan untuk biji kakao yang difermentasi selama 4 dan 6 hari memiliki tekstur yang halus. Untuk perlakuan alkalisasi tidak memberikan pengaruh pada tekstur dari biji kakao. Tingkat kerapuhan untuk seluruh perlakuan yang dipilih kebanyakan panelis adalah agak rapuh, hal ini menunjukkan bahwa baik perlakuan fermentasi dan alkalisasi tidak mempengaruhi tingkat kerapuhan biji kakao. Penilaian secara organoleptik menunjukkan biji kakao yang terbaik adalah biji kakao dengan lama fermentasi 5 hari dan mendapat perlakuan alkalisasi.

Hasil analisis yang dilakukan terlihat bahwa perlakuan fermentasi 4 hari dengan alkalisasi merupakan perlakuan yang terbaik dikarenakan dari analisis-analisis yang dilakukan perlakuan ini memberikan hasil yang terbaik untuk kadar air, asam lemak bebas, dan juga pada uji organoleptik.

\section{Mutu Kakao Hasil Penelitian Kadar Air}

Kadar air biji kakao pada penelitian ini pada umumnya mendekati Standar Nasional Indonesia (SNI) 2323 - 2008, seperti tertera pada Tabel 5. 
Hasil penelitian menunjukkan kadar air biji kakao berlaku untuk semua perlakuan yaitu fermentasi dan alkalisasi karena berdasarkan hasil analisis keragaman untuk kadar air biji kakao bahwa proses alkalisasi tidak berpengaruh nyata untuk kadar air biji kakao.

\section{Lemak}

Kadar lemak biji kakao hasil penelitian pada umumnya memiliki kadar lemak lebih sedikit dari pada kadar lemak awal biji kakao sebagaimana terlihat pada Tabel 7.

Tabel 5. Kadar Air Biji Kakao Hasil Penelitian

\begin{tabular}{ccc}
\hline \multirow{2}{*}{ Kombinasi } & \multicolumn{2}{c}{ Kadar air } \\
\cline { 2 - 3 } Perlakuan & Standar & Hasil \\
& SNI & Penelitian \\
\hline $\mathrm{L}_{0} \mathrm{~A}_{0}$ & $7,5 \%$ & $7,43 \%$ \\
$\mathrm{~L}_{0} \mathrm{~A}_{1}$ & $7,5 \%$ & $7,46 \%$ \\
$\mathrm{~L}_{0} \mathrm{~A}_{2}$ & $7,5 \%$ & $7,49 \%$ \\
$\mathrm{~L}_{0} \mathrm{~A}_{3}$ & $7,5 \%$ & $7,52 \%$ \\
$\mathrm{~L}_{1} \mathrm{~A}_{0}$ & $7,5 \%$ & $7,40 \%$ \\
$\mathrm{~L}_{1} \mathrm{~A}_{1}$ & $7,5 \%$ & $7,42 \%$ \\
$\mathrm{~L}_{1} \mathrm{~A}_{2}$ & $7,5 \%$ & $7,46 \%$ \\
$\mathrm{~L}_{1} \mathrm{~A}_{3}$ & $7,5 \%$ & $7,58 \%$ \\
$\mathrm{~L}_{2} \mathrm{~A}_{0}$ & $7,5 \%$ & $7,80 \%$ \\
$\mathrm{~L}_{2} \mathrm{~A}_{1}$ & $7,5 \%$ & $7,85 \%$ \\
$\mathrm{~L}_{2} \mathrm{~A}_{2}$ & $7,5 \%$ & $7,90 \%$ \\
$\mathrm{~L}_{2} \mathrm{~A}_{3}$ & $7,5 \%$ & $7,95 \%$ \\
$\mathrm{~L}_{3} \mathrm{~A}_{0}$ & $7,5 \%$ & $7,60 \%$ \\
$\mathrm{~L}_{3} \mathrm{~A}_{1}$ & $7,5 \%$ & $7,60 \%$ \\
$\mathrm{~L}_{3} \mathrm{~A}_{2}$ & $7,5 \%$ & $7,63 \%$ \\
$\mathrm{~L}_{3} \mathrm{~A}_{3}$ & $7,5 \%$ & $7,66 \%$ \\
\hline
\end{tabular}

Tabel 7. Lemak Biji Kakao Hasil Penelitian

\begin{tabular}{crc}
\hline \multirow{2}{*}{$\begin{array}{c}\text { Kombinasi } \\
\text { Perlakuan }\end{array}$} & \multicolumn{2}{c}{ Lemak Biji } \\
\cline { 2 - 3 } Stand & Pasil \\
& Penelitian \\
\hline $\mathrm{L}_{0} \mathrm{~A}_{0}$ & $50,18 \%$ & $50,18 \%$ \\
$\mathrm{~L}_{0} \mathrm{~A}_{1}$ & $50,18 \%$ & $50,00 \%$ \\
$\mathrm{~L}_{0} \mathrm{~A}_{2}$ & $50,18 \%$ & $50,05 \%$ \\
$\mathrm{~L}_{0} \mathrm{~A}_{3}$ & $50,18 \%$ & $50,16 \%$ \\
$\mathrm{~L}_{1} \mathrm{~A}_{0}$ & $50,18 \%$ & $49,74 \%$ \\
$\mathrm{~L}_{1} \mathrm{~A}_{1}$ & $50,18 \%$ & $49,50 \%$ \\
$\mathrm{~L}_{1} \mathrm{~A}_{2}$ & $50,18 \%$ & $47,10 \%$ \\
$\mathrm{~L}_{1} \mathrm{~A}_{3}$ & $50,18 \%$ & $48,92 \%$ \\
$\mathrm{~L}_{2} \mathrm{~A}_{0}$ & $50,18 \%$ & $49,92 \%$ \\
$\mathrm{~L}_{2} \mathrm{~A}_{1}$ & $50,18 \%$ & $46,88 \%$ \\
$\mathrm{~L}_{2} \mathrm{~A}_{2}$ & $50,18 \%$ & $46,90 \%$ \\
$\mathrm{~L}_{2} \mathrm{~A}_{3}$ & $50,18 \%$ & $48,97 \%$ \\
$\mathrm{~L}_{3} \mathrm{~A}_{0}$ & $50,18 \%$ & $50,36 \%$ \\
$\mathrm{~L}_{3} \mathrm{~A}_{1}$ & $50,18 \%$ & $48,88 \%$ \\
$\mathrm{~L}_{3} \mathrm{~A}_{2}$ & $50,18 \%$ & $47,70 \%$ \\
$\mathrm{~L}_{3} \mathrm{~A}_{3}$ & $50,18 \%$ & $49,56 \%$ \\
\hline
\end{tabular}

Hasil penelitian mendapatkan produk biji kakao yang memiliki kadar lemak yang rendah, oleh karena itu maka biji kakao yang telah mendapat proses fermentasi dan alkalisasi lebih diminati oleh industry coklat.

pH

$\mathrm{pH}$ pada penelitian ini mengacu pada $\mathrm{pH}$ netral yaitu $7, \mathrm{pH}$ biji kakao pada penelitian ini tertera pada Tabel 6. Setelah proses fermentasi pH biji kakao semakin menjauh netral sehingga dilakukan proses alkalisasi untuk menetralkan pH biji kakao.

Tabel 6. pH Biji Kakao Hasil Penelitian

\begin{tabular}{ccc}
\hline \multirow{2}{*}{ Kombinasi } & \multicolumn{2}{c}{$\mathrm{pH}$} \\
\cline { 2 - 3 } Perlakuan & $\begin{array}{c}\text { Standar } \\
\text { SNI }\end{array}$ & Hasil \\
& 7 & 5,24 \\
$\mathrm{~L}_{0} \mathrm{~A}_{0}$ & 7 & 5,33 \\
$\mathrm{~L}_{0} \mathrm{~A}_{1}$ & 7 & 5,40 \\
$\mathrm{~L}_{0} \mathrm{~A}_{2}$ & 7 & 6,88 \\
$\mathrm{~L}_{0} \mathrm{~A}_{3}$ & 7 & 5,16 \\
$\mathrm{~L}_{1} \mathrm{~A}_{0}$ & 7 & 5,30 \\
$\mathrm{~L}_{1} \mathrm{~A}_{1}$ & 7 & 5,65 \\
$\mathrm{~L}_{1} \mathrm{~A}_{2}$ & 7 & 6,82 \\
$\mathrm{~L}_{1} \mathrm{~A}_{3}$ & 7 & 5,12 \\
$\mathrm{~L}_{2} \mathrm{~A}_{0}$ & 7 & 5,25 \\
$\mathrm{~L}_{2} \mathrm{~A}_{1}$ & 7 & 5,80 \\
$\mathrm{~L}_{2} \mathrm{~A}_{2}$ & 7 & 6,77 \\
$\mathrm{~L}_{2} \mathrm{~A}_{3}$ & 7 & 5,10 \\
$\mathrm{~L}_{3} \mathrm{~A}_{0}$ & 7 & 5,90 \\
$\mathrm{~L}_{3} \mathrm{~A}_{1}$ & 7 & 6,10 \\
$\mathrm{~L}_{3} \mathrm{~A}_{2}$ & 7 & 6,53 \\
$\mathrm{~L}_{3} \mathrm{~A}_{3}$ & 7 \\
\hline
\end{tabular}

Hasil penelitian menunjukkan pH biji kakao yang tidak mendapatkan perlakuan alkalisasi seluruhnya menjauhi $\mathrm{pH}$ netral, tetapi untuk pH biji kakao yang mendapatkan perlakuan alkalisasi setelah fermentasi $\mathrm{pH}$ yang didapat sangat mendekati $\mathrm{pH}$ netral.

\section{Asam Lemak Bebas}

Asam lemak bebas pada penelitian ini pada umumnya lebih rendah dari pada Standar Nasional Indonesia (SNI) 3748:2009 dengan kadar maksimal 1,75\%. Kadar asam lemak bebas biji kakao pada penelitian ini tertera pada Tabel 8. Tinggi kadar asam lemak bebas merupakan sebuah indikator dari kerusakan mutu biji kakao (Langkong, et al., 2009) sehingga SNI menetapkan kadar maksimal asam lemak bebas pada biji kakao. 
Tabel 8. Asam Lemak Bebas Biji Kakao Hasil Penelitian

\begin{tabular}{ccc}
\hline \multirow{2}{*}{$\begin{array}{c}\text { Kombinas } \\
\text { i Perlakuan }\end{array}$} & \multicolumn{2}{c}{ Asam Lemak Bebas } \\
\cline { 2 - 3 } & Standar SNI & $\begin{array}{c}\text { Hasil } \\
\text { Penelitian }\end{array}$ \\
\hline $\mathrm{L}_{0} \mathrm{~A}_{0}$ & Maksimum 1,75\% & $1,96 \%$ \\
$\mathrm{~L}_{0} \mathrm{~A}_{1}$ & Maksimum 1,75\% & $1,56 \%$ \\
$\mathrm{~L}_{0} \mathrm{~A}_{2}$ & Maksimum 1,75\% & $1,77 \%$ \\
$\mathrm{~L}_{0} \mathrm{~A}_{3}$ & Maksimum 1,75\% & $1,83 \%$ \\
$\mathrm{~L}_{1} \mathrm{~A}_{0}$ & Maksimum 1,75\% & $1,59 \%$ \\
$\mathrm{~L}_{1} \mathrm{~A}_{1}$ & Maksimum 1,75\% & $1,44 \%$ \\
$\mathrm{~L}_{1} \mathrm{~A}_{2}$ & Maksimum 1,75\% & $1,35 \%$ \\
$\mathrm{~L}_{1} \mathrm{~A}_{3}$ & Maksimum 1,75\% & $1,46 \%$ \\
$\mathrm{~L}_{2} \mathrm{~A}_{0}$ & Maksimum 1,75\% & $1,64 \%$ \\
$\mathrm{~L}_{2} \mathrm{~A}_{1}$ & Maksimum 1,75\% & $1,50 \%$ \\
$\mathrm{~L}_{2} \mathrm{~A}_{2}$ & Maksimum 1,75\% & $1,35 \%$ \\
$\mathrm{~L}_{2} \mathrm{~A}_{3}$ & Maksimum 1,75\% & $1,42 \%$ \\
$\mathrm{~L}_{3} \mathrm{~A}_{0}$ & Maksimum 1,75\% & $1,78 \%$ \\
$\mathrm{~L}_{3} \mathrm{~A}_{1}$ & Maksimum 1,75\% & $1,67 \%$ \\
$\mathrm{~L}_{3} \mathrm{~A}_{2}$ & Maksimum 1,75\% & $1,58 \%$ \\
$\mathrm{~L}_{3} \mathrm{~A}_{3}$ & Maksimum 1,75\% & $1,54 \%$ \\
\hline
\end{tabular}

Asam lemak bebas untuk biji kakao yang mendapat perlakuan fermentasi seluruhnya berada dibawah batas maksimum, selain itu perlakuan alkalisasi juga semakin menurunkan kadar asam lemak bebas pada biji kakao.

\section{KESIMPULAN DAN SARAN Kesimpulan}

Berdasarkan hasil penelitian yang telah dilakukan, maka penulis menyimpulkan sebagai berikut :

1. Lama fermentasi berpengaruh nyata, perlakuan alkalisasi serta interaksi keduanya tidak berpengaruh nyata terhadap kadar air. Perlakuan terbaik untuk kadar air adalah fermentasi 4 hari.

2. Lama fermentasi, perlakuan alkalisasi, dan interaksi keduanya berpengaruh nyata terhadap pH biji kakao. pH biji kakao setelah fermentasi berkisar antara 5,1-5,24, sedangkan $\mathrm{pH}$ setelah alkalisasi berkisar antara 6,53-6,88. Perlakuan terbaik untuk $\mathrm{pH}$ adalah fermentasi 4 hari dan alkalisasi.

3. Lama fermentasi, perlakuan alkalisasi, dan interaksi keduanya berpengaruh nyata terhadap kadar lemak biji kakao yang dihasilkan. Kadar lemak tertinggi terdapat pada perlakuan fermentasi 6 hari yaitu $50,36 \%$. Sedangkan kadar lemak terendah terdapat pada perlakuan 2 hari fermentasi dan alkalisasi yaitu 48,92\%. Perlakuan terbaik untuk lemak adalah fermentasi 6 hari dan alkalisasi.

4. Lamanya fermentasi, alkalisasi, dan interaksi keduanya berpengaruh nyata terhadap Asam Lemak Bebas (ALB) yang ada pada biji kakao. ALB terendah ada pada fermentasi 4 hari dan setelah alkalisasi sedangkan yang tertinggi adalah pada biji kakao yang tidak mengalami perlakuan fermentasi. Perlakuan terbaik untuk asam lemak bebas adalah fermentasi 4 hari dan alkalisasi.

5. Warna biji kakao yang dominan dipilih oleh para panelis pada uji organoleptik adalah warna coklat, aroma yang dominan dipilih adalah aroma khas coklat, tekstur yang dominan dipilih adalah agak halus, sedangkan untuk tingkat kerapuhan panelis dominan memilih agak rapuh.

\section{Saran}

1. Perlu perlakuan pemeraman sebelum proses fermentasi agar cita rasa dan aroma dari kakao lebih terasa.

2. Perlu perlakuan penelitian lebih lanjut pada periode proses alkalisasi yang berbeda, seperti penggunaan larutan alkali yang berbeda atau konsentrasi yang berbeda.

3. Hendaknya dilakukan perancangan alat untuk pencuci kakao agar proses pencucian maksimal dan memudahkan dalam proses pencucian.

4. Hasil terbaik dijumpai pada perlakukan lama fermentasi 4 hari dengan faktor pemberian $\mathrm{Na} 2 \mathrm{Co} 34 \%$

\section{DAFTAR PUSTAKA}

Atman, A.S. 2006. Pentingnya Proses Fermentasi Biji Kakao. http://www.iptek.net.id $26 \quad$ Februari 2011.

Dini Syafitri. 2010. Teknologi Fermentasi dalam Pengolahan Biji Kakao. Blog Mahasiswa Jurusan Sosial Ekonomi Pertanian. Universitas Andalas. Padang Sumatra Barat.

Elna Karmawati dan Zainal, Ir. 2010. Budidaya dan Pasca Panen Kakao. Pusat penelitian dan Pengembangan Perkebunan. 
Firdaus, AB, Nasriah, A. Yani. 2008. Teknologi budidaya Kakao. Balai Besar Pengakajian dan Pengembangan Teknologi Pertanian.

Herman dan S. Wardani. 2004. Perkembangan dan Prospek Komoditas kakao. J. Tinjauan Komoditas Perkebunan Edisi Juni vol.II (2) : 135-156.

Supriyanto, H. 2012. Teknologi Coklat. Gajah Mada University Press. Yogyakarta.

Susanto, Ir. FX. 1994. Budidaya dan Pengolahan Hasil Tanaman Kakao. Penerbit Kanisius, Yogyakarta.

Langkong, J., E. Ishak., M. Bilang., dan J. Muhidong. 2009. Pemetaan Lemak dari Biji Kakao di Sulawesi Selatan. Jurusan Tehnik Pertanian, Fakultas Pertanian Universitas Hasanuddin. Makassar.

Mulato Sri, Sukrisno Widyatomo, Misnawi, dan Edy Suharyanto. 2005. Pengolahan Produk Primer dan Sekunder Kakao. Pusat Penelitian Kopi dan Kakao Indonesia. Jember.

Purwanti. 2004. Penelitian Laboratorium Analisis dan Organoleptik untuk industri Pangan dan Hasil Pertanian. Jurnal Ilmu Pertanian UGM. Yogyakarta.

Setyohadi. 2002. Dasar-dasar Tehnologi Fermentasi dan Pengeringan Biji Kakao dalam Seminar Energi Surya, Surabaya.

Soetaryo dan Situmorang. (2005). Pengolahan Produk Primer dan Sekunder kakao.
Pusat Penelitian kopi dan kakao Indonesia, Nasution, Z, 1985, pengolahan Coklat, Agroindustri Press, Jurusan tehnologi pertanian, Fakultas Teknologi pertanian, Institut pertanian Bogor. Bogor.

Sudarmadji, Slamet, Haryano, Bambang Suhardi. 1996. Analisa Bahan Makanan dan Pertanian. Pustaka Pertanian. Yogyakarta.

Sunanto, H. 1994. Cokelat, Budidaya, Pengolahan Hasil dan Aspek Ekonominya. Kanisius, Yogyakarta.

Suryani, Dinie, Zulfebriansyah, 2007. Komoditas Kakao : Potret dan Peluang Pembiayaan. Economic Review : 210. Desember 2007.

Wahyudi, T, T.R. Panggabean, dan Pujiyanto. 2008. Panduan lengkap Kakao. Penebar Swadaya. Jakarta.

Widyotomo, S., Sri-Mulato, Suharyanto, E. 2004. Pemecahan Buah dan Pemisahan Biji Kakao Secara Mekanis. Warta pusat penelitian kopi dan kakao Indonesia, Jember.

Widyatomo, Sukrisno. 2008. Teknologi Fermentasi dan Vertifikasi Pulpa Kakao Menjadi Yang Bermutu dan Bernilai Tumbuh. Pusat Penelitian Kopi dan Kakao Indonesia. Review Penelitian Kopi dan Kakao. 24(1), 65-82. 